\title{
A UTOPIA CONCRETA DO HOMEM CORDIAL ${ }^{1}$
}

\author{
[ THE CONCRETE UTOPIA OF CORDIAL MAN ]
}

\author{
Suzana Albornoz * \\ Universidade Federal do Rio Grande-FURG, Brasil
}

\begin{abstract}
Resumo: Este artigo trata da Utopia como conceito determinante e chave filosófica em Ernst Bloch. O Princípio esperança, obra principal do nosso autor, pode ser interpretado, de maneira geral, como uma fenomenologia das utopias. Nesse sentido, o artigo aborda conceitos como utopias médicas, da saúde; utopias sociais, da ordem e da liberdade, não deixando de abordar as utopias científicas, bem como as técnicas, da natureza e da vontade. Entre outras coisas, isto é o que trata o volume 2 desta obra, para ficarmos numa ilustração geral. Não menos interessante é a forma como são tratadas as utopias propriamente filosóficas, da busca da medida e do processo, no sentido em que a abordagem não se furta ao chão da experiência da luta social, da utopia do trabalho digno, que busca a paz, o tempo livre e o lazer, ou seja, uma utopia concreta.
\end{abstract}

Palavras-chave: Princípio esperança; utopia; utopia concreta; paz social
ABstract: This paper seeks to present the concept of Utopia as both a philosophical key and a determining concept in Ernst Bloch's work. "O Princípio Esperança", the main work by Bloch, can be described as an interpretation of the phenomenology of multiple utopias. As such, this article addresses concepts such as medical and health utopias, social utopias of order and freedom, scientific utopias, and techniques of nature and will. Those are, among other things, the concepts dealt with by the second volume of Bloch's work. Nonetheless, the properly philosophical utopias, as in the pursuit of measurement and process, are treated in a similarly interesting way, as Bloch's approach does not deviate from the experience of social struggle, the utopia of honest work, the search for peace, free time, and leisure; that is to say, a concrete utopia.

KEYWORDS: Hope principle; Utopia; concrete utopia; social peace

que se entende por utopia? O que têm sido as utopias? O que significa uma Brasil cordial? O que favorece o Brasil cordial?

\section{O QUE SE ENTENDE POR UTOPIA?}

Ao responder a essa pergunta inicial, vemos que a palavra não é muito antiga, pois sua invenção é atribuída ao filósofo e político da Renascença inglesa, sir Thomas $\mathrm{More}^{2}$, que intitulou Utopia o seu romance político publicado em 1516. A origem da

* Universidade de Santa Cruz do Sul, UNISC, Brasil. Universidade Federal do Rio Grande, FURG,Brasil.m@ilto: albornoz.suzanaguerra@gmail.com 
palavra utopia é grega; ela surge da associação do sufixo grego où - que indica a negação, com tópos - que significa lugar, resultando em oùtópos - o "não lugar", ou melhor, "aquilo que não tem lugar". Na palavra utopia se articulam dois conceitos que lhe dão conotações múltiplas: où-topos - não-lugar, e eu-tópos - lugar ideal, a cidade perfeita. Por isso, a palavra utopia carrega uma ambiguidade, pois alude ao mesmo tempo à cidade inexistente, impossível, e à cidade sonhada.

\section{O QUE TÊM SIDO AS UTOPIAS?}

A história me parece ser um bom caminho para a compreensão de algo; é sem dúvida um bom método de estudo. Um pouco de história ajuda a contextualizar o assunto, a entender melhor os aspectos envolvidos no problema. Logo, para introduzir o nosso tema central, que é a utopia concreta do homem cordial, convido a considerar, ainda que brevemente, a evolução moderna do termo desde que foi usado pela primeira vez, e espero que assim fique mais claro o fenômeno e o conceito.

Não se pode negar a existência de antecedentes de cidades idealizadas em textos mais antigos, em reflexões na história da filosofia, como é o caso da República, de Platão, e A Cidade de Deus, de Santo Agostinho, ou em relatos fora da filosofia, mesmo fora da literatura, no tesouro das religiões como o Éden perdido, da tradição bíblica, e a Terra sem Males, dos indígenas guaranis, ou na memória oral dos povos e no folclore, onde se guardam as lendas da Schlaraffenland, dos povos germânicos europeus, e o País de Cocanha, dos latinos, que ainda ecoam na Pasárgada do poema de Manuel Bandeira. Mas especialmente na Renascença, no início dos tempos modernos, talvez por inspiração das viagens dos navegadores que se multiplicaram na época, a cidade ideal deu consistência a um verdadeiro gênero literário, no qual se evocam terras fantásticas e míticas como o Eldorado, a Atlântida e a misteriosa Ilha de São Brandão. Entre os muitos romances políticos renascentistas de que se tem notícia, além da Utopia de More e $A$ cidade do sol do italiano Campanella, destaca-se $A$ nova Atlântida de Francis Bacon, na qual se anteciparam, como que se profetizaram muitos dos inventos modernos dos últimos séculos da ciência e da técnica.

No século XVI, enquanto florescia sob a influência das viagens e descobertas geográficas, pelo encontro de outros povos em lugares antes desconhecidos do planeta, a literatura utópica foi considerada inimiga da realidade. Mantinha-se um severo julgamento em relação à obra dos sonhadores de cidades ideais, considerados como meros propagadores de "castelos no ar", de realização impossível. E ainda durante os séculos XVII e XVIII, quando tais obras não foram escassas, chamavam-se de utopias as imaginações irrealistas, ideias extravagantes ou quimeras, planos sonhadores que o bom senso recomendava superar pelo tino prático ou pelo costume mais premente, embora não fossem poucos - por exemplo, na Inglaterra, os autores imaginativos em busca da efetivação dos mundos sonhados, às vezes em relação com as reformas religiosas da época.

No próprio Século das Luzes, na França, quando se defendia de modo acentuado a predominância da razão, a imaginação utópica se fez muito presente. As revoluções políticas burguesas, tanto no mundo anglo-saxão, de um lado e outro do Atlântico, como na Europa, de um e outro lado da Mancha, aliaram às lutas teóricas e práticas, dos princípios da filosofia política e do direito, e aos interesses econômicos e sociais baseados nas situações mais concretas, a expectativa do progresso humano, da inovação histórica, do "mundo melhor". E assim como entre realismo e idealismo no plano filosófico, e entre a tendência conservadora e a revolucionária na prática política, as 
contradições se mantiveram também no plano das metas, entre a procura técnica de melhores formas de vida e a busca sonhadora, com abertura para o novo. Todavia, no movimento destas contradições, nesse caldo secular de produção do espírito e da imaginação criativa, as utopias literárias se abriram para as utopias práticas.

Fato é que o tempo da ciência foi também o da utopia, e o século XIX, que se tornou célebre como "o Século da Ciência", foi dos períodos em que mais se afirmaram as utopias e o impulso de reforma prática, política e social, embora mesmo então predominasse o sentido pejorativo da expressão "utopia", de modo que os próprios pensadores e doutrinadores da época, que entraram para a história como socialistas utópicos, negavam o caráter utópico dos seus programas e projetos sociais.

Este não é o momento para descrever as especificidades teóricas e as sugestões práticas de cada um dos reformadores que se fizeram notar naquele período histórico, ${ }^{3}$ contudo, convém nomeá-los ao menos de passagem, para não desperdiçar a ocasião de recomendar o seu estudo tantas vezes esquecido, quando não menosprezado. Na França, onde o fenômeno foi marcante, destacaram-se, entre outras, as obras de Henri de SaintSimon(1760-1825), Charles Fourier(1772-1835), Pierre Leroux(1778-1871), PierreJoseph Proudhon(1809-1865) e Louis Blanc (1811-1882; e na Inglaterra, especialmente a de Robert Owen(1771-1858). Algumas vezes lhes tem sido também associado JeanJacques Rousseau (1712-1778), muito embora a contribuição do autor do Emílio, em amplitude de influência, transcenda o fenômeno denominado socialismo utópico.

Por todo o XIX e em parte do século XX, a utopia se manteve presente no coração do debate, especialmente do pensamento político associado à ciência social crítica da sociedade burguesa e da tradição, atenta à história e à práxis dos movimentos sociais e conflitos da sociedade industrial. Porém, na própria ciência social crítica o pensamento utópico permaneceu como sinal de contradição, pois foi crítica da utopia a posição predominante no pensamento marxista, de Karl Marx (1818-1883), Friedrich Engels (1820-1895), e seus discípulos e continuadores. E para melhor compreender a relação do marxismo com a utopia, vale consultar o famoso texto Do socialismo utópico ao socialismo científico, publicado por Engels em 1890. A contradição se manteve e o socialismo científico se opôs ao socialismo utópico em suas referências mais importantes, como Vladimir Lenin (1870-1924), Eduard Bernstein (1850-1932), Rosa Luxemburgo (1871-1919), Karl Kautsky (1854-1938) ou Léon Trostsky (18791940), e Georg Lukàcs(1885-1971), entre outros, embora os críticos do socialismo e do comunismo muitas vezes os tenham criticado como "utopias".

No início do século XX, por efeito dos caminhos e descaminhos das lutas sociais e políticas, no avançar da sociedade industrial, certamente em ligação com os progressos e frustrações da ciência e da técnica, e sob a experiência dolorosa da primeira guerra mundial que antecipava a tragédia da segunda - ambas terríveis e incomparáveis, operou-se uma mudança na compreensão da relação, tensional e dialética, entre utopia e realidade, havendo como que uma aproximação entre elas, um movimento de reabilitação, de mais respeito pela contribuição positiva da utopia, que é vista como útil para a prospecção e o planejamento, e como crítica do real, portanto, potência de transformação. Um exemplo marcante a ser lembrado é o da sugestão feita por Bertrand Russell (1872-1970), de uma autoridade internacional, ante o drama da guerra e a necessidade da paz mundial.

É então que surge uma nova concepção de utopia, um novo entendimento do aparentemente impossível não existente, que se propõe para realização. Ao mesmo tempo, cresce a consciência da ligação estreita entre o progresso científico e a imaginação antecipadora. Tal ambiente, no início do século XX, prepara o surgimento do conceito de utopia concreta, que amadureceria numa grande obra e seria exposto, de 
quase infinitas maneiras, nos inúmeros trabalhos da filosofia de Ernst Bloch (1885$1977)^{4}$.

\section{O QUE SIGNIFICA UMA UTOPIA CONCRETA?}

Mesmo na filosofia prática que se ocupa com os homens como seres que desejam e sonham, que agem e buscam tornar o mundo melhor, é grande o cuidado com a precisão conceitual, pois a filosofia se entende em grande parte como o trabalho dos conceitos. Por isso me parece poder dizer que o pensamento de Ernst Bloch é a filosofia da utopia concreta, no sentido de que esse conceito é o eixo central daquele sistema filosófico ${ }^{5}$. Convido a que me acompanhem na tentativa de compreensão desse conceito novo - de utopia concreta, tal como o pensou aquele pensador.

O primeiro grande livro de Bloch - Espírito da utopia (1918), que há pouco completou um século e está sendo traduzido no Brasil - já prenunciava uma filosofia da utopia, ali mediada por uma erudita reflexão sobre a música. Revisto e publicado em sua forma definitiva em 1923, esse belo ensaio pode ser considerado como uma introdução à filosofia da utopia na forma de uma filosofia da música. Desde Espírito da utopia (1918/1923) até Experimentum mundi(1975), mediante uma sofisticada linguagem literária, altamente erudita, Bloch explicitou uma nova valoração do elemento utópico na história humana, considerando de modo sui generis as obras da imaginação, construindo uma antropologia que afirma o homem como um ser de pulsões, de fomes e de sonhos, aberto para o mais e para o novo. Tal antropologia, fundada num modo de ver o homem como ser incompleto em busca de realização, como ser em possibilidade, encontra expressão numa linguagem barroca, de dimensões metafísicas, onde se afirma o ser do mundo como possibilidade, como aberto para o ainda não ser.

No pensamento deste filósofo que, enquanto judeu alemão e socialista, acompanhou as vicissitudes da "era dos extremos"- expressão do historiador Eric Hobsbawn(1917-2012) para o século XX -, utopia e realidade não se excluem, antes se articulam e completam, e os sonhos humanos, mesmo o que neles há de utópico no sentido vulgar daquilo que hoje não existe e parece improvável, podem ser sinais do que ainda não é mas pode vir a ser. Sobretudo em O princípio esperança(1959), considerado como sua obra-prima, constrói-se um verdadeiro sistema em torno do conceito de utopia concreta.

O grande livro Princípio esperança pode ser interpretado como uma fenomenologia das utopias. O V.2 inicia pelas utopias médicas, da saúde; passa pelas utopias sociais, da ordem e da liberdade; não deixa de se ocupar a fundo com as utopias científicas, bem como as técnicas, da natureza e da vontade; e fascina o leitor ao apresentar as utopias arquitetônicas, inspiradas nos arquétipos do cristal e da árvore da vida. Leva-nos a viajar com as utopias geográficas, da busca do Éden e do Eldorado; vai às utopias artísticas, na música, na pintura e em todas as artes; para chegar às utopias propriamente filosóficas, da busca da medida e do processo; e não se furta ao chão da experiência da luta social, da utopia do trabalho digno, que busca a paz, o tempo livre e o lazer. O V.3 culmina com a reflexão sobre as imagens do desejo na moral, na música, na religião, na busca do absoluto, alma do sonho e do impulso para o melhor. Mas é no V.1 onde se encontra a fundamentação do conceito de utopia concreta que desejamos referir aqui.

A fenomenologia dos sonhos humanos mostra que, além dos sonhos noturnos, onde emerge o passado e o já não consciente, na experiência dos sujeitos existem 
sonhos diurnos ou acordados, que elaboram as possibilidades do real para o futuro. Entre os sonhos acordados ou utopias, distinguem-se as abstratas das concretas. Utopias abstratas são sonhos impossíveis de realizar, porque são sonhos de um só indivíduo, imaginações fantasiosas, quimeras, ou invenções literárias sem possibilidade de realização. Utopias concretas são sonhos passíveis de efetivação - porque transcendem o indivíduo, pois são sonhos coletivos, mas também porque se fundamentam nas possibilidades reais. Os sonhos humanos coletivos elaboram possibilidades do real e estão sujeitos a diferentes níveis de possibilidade. A utopia concreta se fundamenta na possibilidade real.

Apresentei já, em diversas ocasiões, os níveis da categoria da possibilidade conforme Princípio esperança (V.1,Cap.XVIII) ${ }^{6}$. Apenas relembro aqui mais uma vez, brevemente: O primeiro nível do possível é o possível formal, que pode ser um possível formal apenas do plano da linguagem, ou um possível formal no plano do pensamento. O segundo nível do possível é o possível subjetivo, ou provável, dito também como possível objetivo factual, onde se está no plano das previsões e estimativas, seja daquelas menos fundadas, sem base científica, ou das suposições bem fundadas, segundo o estado atual dos conhecimentos. O terceiro nível do possível é o possível objetivo segundo a estrutura da coisa, aquilo que o sujeito muitas vezes não pode aquilatar, mas é dado como possibilidade objetiva, à espera da intervenção externa. $\mathrm{O}$ quarto nível do possível é o possível subjetivo-objetivo ou dialético; é o plano do possível real. Esse é o plano da utopia concreta, que se torna realidade quando condições objetivas se encontram com condições subjetivas. O possível da possibilidade real caracteriza a utopia concreta. Nesse plano do possível há uma brecha para a liberdade, quando se dão condições objetivas e subjetivas e, assim, mediante a intervenção humana, os acontecimentos encontram realização. Esse é o conceito de utopia concreta que se pode realizar, porque tem base no real ao mesmo tempo objetivo e subjetivo. Gostaria de deixa-lo aqui guardado, em suspenso, para servir à reflexão sobre a utopia brasileira do homem cordial, que proponho a seguir.

\section{O HOMEM CORDIAL É UMA UTOPIA CONCRETA?}

Neste momento, um mês após a eleição para a Presidência da República do Brasil de um representante da extrema-direita que faz propaganda das armas, apoia a tortura, a repressão e o combate violento aos partidos progressistas, soa como utopia abstrata afirmar o brasileiro como um povo cordial. Depois das vicissitudes políticas que atravessamos nestes últimos anos, com o ataque midiático, policial e judicial ao Partido dos Trabalhadores, por tendenciosos processos que culminaram no golpe parlamentar travestido de impeachment, que afastou o governo legitimamente eleito da presidente Dilma Rousseff em 2016, e culminou com a condenação e prisão do expresidente Luiz Inácio Lula da Silva, impedido de concorrer às eleições em 2018; e após a derrota das forças democráticas na campanha eleitoral eivada de recursos duvidosos e mesmo criminosos, temos muito conscientes os nossos defeitos tradicionais de conservadorismo e de alienação, assim como nossos vícios de desigualdade econômica, social e política.

Por outro lado, um dos mais reconhecidos sociólogos brasileiros da atualidade, Jessé Souza, tem insistido muitas vezes em chamar a atenção para o enganoso que há em algumas interpretações clássicas do Brasil, que parecem esconder nosso lastro negativo da longa submissão colonial bem como a marca secular da escravidão. Parecem-me justas as críticas de Jessé Souza, sobretudo quando se refere à tendência de 
alguns intelectuais brasileiros a atribuir ao poder do Estado a razão de nossos males, e a ver na ordem política o âmbito da corrupção, lado avesso de uma idealização moralista do âmbito privado.

Parecem-me ter razão os estudiosos que nos relembram que a história do Brasil tem sido marcada por muita violência, com persistente dependência de forças estrangeiras, além de grande autoritarismo interno, sob o peso de uma elite do atraso ${ }^{7}$ e de uma classe média muitas vezes cúmplice e, em grande parte, omissa. Todavia, apesar das observações críticas e das análises realistas dos cientistas sociais e historiadores, não me parece que se devam descartar todas as brilhantes intuições dos primeiros intérpretes do Brasil, que nos podem servir para novas interpretações.

Antonio Cândido (1918-2017) ${ }^{8}$, figura ímpar entre os mestres brasileiros, foi um dos autores que se ocuparam com os "livros que inventaram o Brasil"- entre os quais são sempre lembrados Casa Grande \& Senzala(1933) de Gilberto Freyre(1900-1987), Raízes do Brasil(1936) de Sérgio Buarque de Holanda(1902-1982), e A formação do Brasil contemporâneo(1942) de Caio Prado Junior(1907-1990) ${ }^{9}$.

Na apresentação à edição de 1967 de Raízes do Brasil, o grande crítico faz um resumo das diferenças de mensagem política existentes entre aqueles três livros fundadores, que foram além da historiografia antes existente, muito marcada por preconceitos ideológicos, e conseguiram exprimir o que ele chama de radicalismo intelectual e análise social, mentalidade surgida após a Revolução de 1930 e que teria sobrevivido mesmo às vicissitudes sofridas pela liberdade de pensamento durante o período do Estado Novo. Influenciadas por diferentes paradigmas científicos, cada uma daquelas obras realizaria essa expressão de um modo distinto e, assim, sua análise tomou diferente sentido político. Raízes do Brasil, cronologicamente situada entre os três grandes livros, expressaria um veio menos conhecido do pensamento político-social brasileiro, que Antonio Cândido chama de "radicalismo das classes médias".

O conceito de cordial usado por Buarque de Holanda para se referir, digamos, ao homem médio brasileiro como homem cordial $^{10}$, tem suscitado contestações e dúvidas, mas me parece expressar uma intuição inspiradora que desafia para novas compreensões. Em nota do capítulo assim intitulado ${ }^{11}$,o autor esclarece que não inventou a expressão ${ }^{12}$,e que não desejava com ela aludir a juízos éticos, nem tinha intenções apologéticas, portanto, quando falava em cordialidade e em homem cordial, não queria significar exatamente "bondade" ou "homem bom". Aolanda o cordialidade por ele atribuída aos brasileiros não abrange apenas sentimentos positivos e de concórdia, uma vez que a inimizade poderia ser tão "cordial" como a amizade no sentido de que uma e outra nascem do coração ou, dito de outro modo, procedem da esfera do íntimo, do familiar, do privado.

Aliás, a distinção entre o público e o privado é crucial na análise de Raízes do Brasil, onde se afirma não só uma gradação, mas uma descontinuidade, mesmo uma oposição entre o círculo familiar e o Estado. Tal oposição pode servir como chave de interpretação e de compreensão do capítulo e do livro, onde o autor defende que, no Brasil, o homem cordial, ligado às relações afetivas e aos fortes elos de família, toma dianteira sobre o homem civil e precede ao cidadão, ao indivíduo consciente de ser membro de um Estado - o que parece ser bem realidade, embora o avaliemos de forma menos benevolente.

Ainda quando salienta que a cordialidade nem sempre é positiva, que não é só bondade o que se vê no modo brasileiro de agir "segundo o coração", há um momento em que o autor se refere à cordialidade como a uma promessa, associada a uma “expressão feliz": Já se disse, numa expressão feliz, que a contribuição brasileira para a civilização será de cordialidade - daremos ao mundo o "homem cordial". ${ }^{13}$ 
As virtudes muitas vezes louvadas pelos estrangeiros que aqui passaram como viajantes - gentileza no trato, hospitalidade, generosidade, porta e mesa abertas, autorizariam sua consideração como traço do "caráter brasileiro". E mesmo se compreendermos cordial no sentido mais comum, que remete a um ethos positivo, de bom convívio, parece-me interessante aceitar a sugestão de Holanda - de interpretar o brasileiro como homem cordial, não como uma descrição de realidade, mas como o desenho de uma possibilidade, como um modelo, que pode servir de inspiração para o Brasil. Eu gostaria de me apropriar dessa definição e assim, sem cair no moralismo ingênuo, ampliar o conceito e transforma-lo, para propor a sua interpretação como uma utopia concreta.

Que o brasileiro homem cordial não é uma realidade geral no país, isso parece ser uma constatação tranquila, de consenso. Mas por que essa intuição deveria ser vista como um engano ou um mito? Por que deveria ser vista como utopia abstrata, impossível de se realizar? A cordialidade brasileira não é uma realidade coletiva e completa, contudo, tem lugar no plano da realização eventual e, sobretudo, é uma real inspiração, e assim, pode ser considerada como uma utopia concreta. Bases objetivas e subjetivas estão dadas para que seja realizada, pelo menos em parte. Bases objetivas se encontram já nos recursos materiais do nosso país continente, disponíveis na natureza pródiga, no plano da fecundidade do solo, das riquezas de subsolo, da diversidade biológica, da abundância de água e sol e acesso a energias limpas; tudo isso é favorável para a organização de um povo em convívio amigável com a natureza, o que favoreceria o próprio convívio entre os diversos grupos sociais. Bases subjetivas também estão dadas na disposição convivial e no desejo de melhoria de vida da maioria do povo que, em tantas situações de observação da vida cotidiana, parecem confirmadas pelos registros de seus séculos de história, e tem demonstrado ser capaz de resistência, de solidariedade, de resiliência, de superação. Bases subjetivo-objetivas podem desenvolver-se no plano social e político, na vivência da liberdade com mais igualdade, na construção da vida democrática e no estado de direito, que ainda não consolidamos.

\section{O QUE IMPEDE O BRASIL CORDIAL?}

Evidentemente, a violência impede de realizar-se a utopia concreta de um Brasil cordial, mais igualitário, mais justo e mais feliz. A violência esteve presente em toda a história brasileira e, infelizmente, ainda hoje não encontra boas soluções. A violência dos poucos e mais fortes, contra os muitos e mais fracos, é o contrário da cordialidade e impede a realização da utopia concreta do brasileiro cordial. A violência é alimentada pela ignorância, fonte de preconceitos, criadora de medos irracionais. Alimentam a violência o atraso conservador e o assédio ideológico, através da imprensa partidarizada, especialista em desinformação, e também mediante as religiões fundamentalistas.

Dão suporte à violência os interesses capitalistas, dos grupos financeiros globalizados, dos jogos geopolíticos de dominação, das corporações multinacionais, sobretudo, das indústrias do armamento, mineradoras e petroleiras. Multiplica-se a violência pelos conflitos internos, desigualdades de classe, diferenças culturais e ideológicas, e as redes de segurança policiais e militares. O ápice da violência é o encarceramento injusto, o tratamento arbitrário e desumano, muitas vezes em relação com a criminalização das drogas e do pequeno tráfico, associada à falta de julgamento de tantos pequenos delitos e ao abandono pela Justiça da classe despossuída. Potencializa-se a fábrica de violência com os escândalos jurídicos por motivos 
políticos, e sucumbe ante a violência o poder judiciário politizado e a política judicializada, que considera acusações mentirosas de caráter vingativo e criminaliza os movimentos sociais. Em diversos planos do real a violência se opõe à utopia concreta do homem cordial, o que recapitulo e repito: No plano dos interesses econômicos globais, dentro de jogos geopolíticos de dominação, de grupos financeiros globalizados e das corporações multinacionais. No plano das instituições judiciais, onde se dá como Justiça de exceção, do judiciário politizado; nas estruturas de controle, de repressão, de pena, e pela polícia classista e racista, nas redes de segurança policiais e militares, também paramilitares. Como atraso social, na conservação de privilégios de classe, na destituição de direitos, do conservadorismo retrógrado, na ameaça às minorias, no combate aos movimentos sociais, e no assédio ideológico, da imprensa partidária, das religiões fundamentalistas. Em suma, no plano da conservação da ignorância, dos preconceitos, dos medos, assim como na desigualdade de oportunidades de educação.

Violência e cordialidade se confrontam, e o confronto entre cordialidade e violência faz parte da dinâmica da vida brasileira. É ingênuo supor a possibilidade de um país todo cordial, sem nenhuma violência, numa realização total da utopia como eutopia. Porém, também seria pura expressão de falta de autoconfiança e de autoestima, supor um Brasil todo violência, sem capacidade de melhorar seu modo de vida ou de aperfeiçoar a organização do convívio comum. Violência e cordialidade são polos constantes, em oposição persistente, não só em nosso país. Continuará a luta entre o impulso coletivo para um país mais solidário e cordial, de um lado, e o sistema repressor que deseja anular os desejos da maioria, para maior submissão a favor dos interesses do capital, do outro. Para afirmar a cordialidade ante a violência; para criar mais cordialidade e ter menos violência, é preciso trabalhar por um projeto de transformação econômica, social e política, em favor de uma vida com mais liberdade e menos desigualdade.

\section{O QUE FAVORECE O BRASIL CORDIAL?}

O Brasil cordial não existe, portanto, atualmente é uma utopia, no sentido primeiro da palavra. No entanto, não me parece ser uma utopia abstrata, no sentido de impossível. É real, enquanto um sonho que pode tornar-se projeto e, pela ação, vir a implantar-se na realidade, logo, o Brasil do homem cordial pode ser considerado uma utopia concreta. O projeto do Brasil de acordo com esse sonho começa pela criação de igualdade de oportunidades, pelo trabalho digno que leva à inclusão na produção e no consumo, e se realiza pela expansão educativa, a cidadania cognitiva, a consciência ética, a cultura da paz. O que o começa e o que o termina? É difícil precisar. Mas para caminhar no sentido dessa realização, segundo esse sonho e esse projeto, é condição trabalhar por uma sociedade que ofereça mais igualdade de oportunidades - o que exige ousar mudanças estruturais, para proporcionar ao grande número o trabalho respeitado, e assim prover a saúde e a qualidade de vida, e tudo isso parece terminar ou começar pela educação. Pois a expansão educativa, ou melhor - assumindo a expressão de Renato Janine Ribeiro - a cidadania cognitiva ${ }^{14}$ é o que possibilita mais saúde, mais qualidade de participação e mais autonomia no trabalho; ou seja, mais liberdade, maturidade social, consciência ética, cultura política, e consequentemente, cultura da paz e vivência da cordialidade.

Muitos dos grandes filósofos na história clássica da filosofia - tão separados no espaço e no tempo como Aristóteles, na Antiguidade grega, e Emanuel Kant, no Iluminismo alemão ${ }^{15}$ - terminaram suas obras de filosofia prática pela recomendação de 
buscar com afinco a realização e o aperfeiçoamento dos seres humanos, através da educação. Assim também aparece em muitas das utopias literárias, naqueles romances políticos que imaginaram cidades perfeitas a que aludimos no início desta apresentação. Contudo, neste momento tendo a pensar diferente daquilo que escreveram tão grandes mestres - ao indicar a educação como instrumento para aperfeiçoar o ser humano, a sociedade, "o mundo"-, e inclino-me a dizer que a educação não é apenas o instrumento mas, sim, a meta, pois somente através do desabrochar da obra educativa se pode realizar a utopia concreta de um país mais justo e mais cordial.

Para a retomada dessa construção, neste momento difícil de retrocesso do Brasil sob ataque dos inimigos do sonho da sociedade cordial, onde pode ocorrer a expansão educativa, científica e cultural; dentro da violência da guerra híbrida instaurada na atualidade; não podemos esquecer um fato pontual, particular mas de relevância geral, de importância essencial para a democracia e para o estado de direito brasileiro; de máxima força simbólica, que é a injusta prisão e necessidade de libertação do nosso caro ex-presidente Luiz Inácio Lula da Silva, aprisionado injustamente porque sem provas; sem razões suficientes para sequer ser acusado, e sem haver sido justamente julgado; portanto, preso político desde abril de 2018, vítima de um evidente processo de Lawfare, sem o menor decoro e por motivos fáceis de deduzir, da ordem dos interesses tacanhos que ameaçam a evolução social e a soberania nacional do Brasil.

\section{REFERÊNCIAS}

Albornoz, S. Ética e utopia (1985). Porto Alegre: Movimento/Edunisc, 2006.

Albornoz, S. O enigma da esperança. Petrópolis: Vozes, 1998.

Albornoz, S. O exemplo de Antígona. Porto Alegre: Movimento, 1999.

Albornoz, S. Violência ou não violência. Santa Cruz do Sul: Edunisc, 2000.

Albornoz, S. Trabalho e utopia na modernidade. Porto Alegre: Movimento/Nova Harmonia, 2011.

Albornoz, S. Política e vocação brasileira. Porto Alegre: Editora Fi, 2017.

Bloch, E. O princípio esperança (1959). Rio de Janeiro: Contraponto/EdUerj, V.1, 2005.

Holanda, S. B. Raízes do Brasil (1936). São Paulo: Cia Das Letras, 1995/Schwarcz, 2010.

Ribeiro, R.J. A pátria educadora em colapso. São Paulo: Três Estrelas, 2018.

Souza, J. A elite do atraso. Rio de Janeiro: Casa da Palavra/Leya, 2017.

\section{Notas}

1 Este texto corresponde aproximadamente à Conferência apresentada em 3.12.2018, na Abertura do I Colóquio Nacional de Filosofia Prática, promovido pelo Programa de Pós-Graduação em Filosofia na Universidade Federal da Paraíba, em João Pessoa, de 3 a 5 de dezembro de 2018.

2 Thomas More(ou Morus) viveu de 1478 a 1535. Foi acusado injustamente e condenado à morte pelo soberano inglês da época. Quatro séculos mais tarde, em 1935, foi declarado santo pela Igreja Católica Romana.

3 A respeito, remeto a Trabalho e utopia na Modernidade - de Thomas More a Paul Lafargue (Movimento/Nova Harmonia, 2011).

4 A propósito de Bloch, remeto a Ética e utopia - Ensaio sobre Ernst Bloch (Movimento/Edunisc, 1985; 2a ed. 2006); O Enigma da Esperança. Ernst Bloch e as margens da história do espírito (Vozes, 1998); Violência ou não-violência. Um estudo em torno de Ernst Bloch (Edunisc, 2000), e especialmente, às indicações bibliográficas que ali se encontram.

5 Dia 4.12.2018 foi defendida ante o PPG-Filosofia desta Universidade-UFPB a tese sobre Ernst Bloch da Profa. Marta Maria Aragão Maciel. Na programação daquele Colóquio foi 
prevista a ocasião de apresentação do resumo daquela tese, o que me alegrou, por ver o autor da filosofia da utopia começar a ser conhecido pelos jovens estudiosos de filosofia no Brasil e, ao mesmo tempo, por sentir nesse trabalho a garantia de complementação a esta breve conferência.

6 Remeto especialmente aos dois primeiros capítulos de $O$ enigma da esperança (Vozes, 1998).

1307 Expressão de Jessé Souza, título de uma de suas obras mais conhecidas.

8 A. Candido, "O significado de Raizes do Brasil”, apresentação à edição de 1967; reed. 2010, p.

9. Também Darcy Ribeiro e Fernando Henrique Cardoso, entre outros, acentuaram o caráter inaugural, daqueles três grandes livros, como "os textos que inventaram o Brasil".

9 Aos quais eu tendo a acrescentar O povo brasileiro, de Darcy Ribeiro (1922-1997).

10 B. de Holanda, (1936) 2010, Cap.5, 139-151. Ver meu "Do homem cordial de Sérgio Buarque de Holanda", em Política e vocação brasileira - Leituras transdisciplinares, $2^{\mathrm{a}} \mathrm{ed}$., Editora Fi, 2017, p.248 e ss.

11 “O homem cordial”, B. de Holanda, Raizes do Brasil,(1936) 2010, nota 6, 204.

12 A expressão "homem cordial" seria do escritor Ribeiro Couto, que a usou em carta dirigida a Alfonso Reyes, por este inserida em sua publicação Monterrey.

13 SBH, 2010, 146.

14 Cidadania cognitiva é uma formulação inspirada do professor, filósofo e político, ex-Ministro da Educação, Renato Janine Ribeiro, em A pátria educadora em colapso, 2018, p.225 e ss.

15 Ver "Ética e educação. Reflexões sobre uma relação complexa", in O exemplo de Antígona, 1999, p.89-90. 